\title{
The Results of Unilateral Osteotomy to Correct the Deviated Nose
}

\author{
Jung Heob Sohn, Kijin Lee, and Kyoung Rai Cho \\ Department of Otolaryngology-Head and Neck Surgery, Sanggye Paik Hospital, Inje University College of Medicine, Seoul, Korea
}

\section{휘어진 코를 교정하는 편측 절골술의 효과}

손정협 · 이기진 · 조경래

인제대학교 의과대학 상계백병원 이비인후-두경부외과학교실

\author{
Received May 31, 2017 \\ Revised July 6,2017 \\ Accepted July 11, 2017 \\ Address for correspondence \\ Kyoung Rai Cho, MD, PhD \\ Department of Otolaryngology- \\ Head and Neck Surgery, \\ Sanggye Paik Hospital, \\ Inje University College of Medicine, \\ 1342 Dongil-ro, Nowon-gu, \\ Seoul 01757, Korea \\ Tel +82-2-950-1104 \\ Fax $+82-2-935-6220$ \\ E-mail elysion@hanmail.net
}

Background and Objectives Osteotomy, usually carried out bilaterally, is a commonly performed procedure to correct the bony dorsum of deviated nose. However, it is an invasive maneuvers which can affect the stability of nasal bone and develop complications, such as, edema and ecchymosis. This study aims to evaluate the usefulness of unilateral osteotomy in correcting a deviated nose with various scoliosis.

Subjects and Method We studied 9 of the 69 patients who underwent corrective rhinoplasty with unilateral osteotomy to correct the bony nasal dorsum between 2010 and 2014. For patients whose bony nasal dorsum was corrected well after performing osteotomy on the convex side of the bony dorsum, the opposite side was not operated on; however, if correction was incomplete, osteotomy was additionally performed on the opposite side. For this study, patients who underwent bilateral osteotomy were excluded from the study. The improvement of correction was assessed by comparing the preoperative and postoperative photos.

Results Of the nine patients treated with unilateral osteotomy, 5 cases were $\mathrm{C}$ or reverse $\mathrm{C}$ type deviations, 1 case was $\mathrm{S}$ type deviation and 3 were straight deviations. Five of the nine patients improved greatly and the rest improved significantly. None of the patients experienced worsening change postoperatively.

Conclusion Osteotomy is essential but invasive maneuver, so it is desirable to reduce the number of times to execute. By performing osteotomy on the convex side of the nose first, we can correct the deviated nose effectively while reducing the number of implementation. Korean J Otorhinolaryngol-Head Neck Surg 2017;60(11):559-64

Key Words Deviated nose · Osteotomy $\cdot$ Rhinoplasty.

\section{서 론}

절골술(osteotomy)은 휘어진 코의 골부 만곡을 교정하거나 매부리코 교정 수술 시 발생하는 열린지붕변형(open roof deformity)을 해결하기 위해 보편적으로 사용되지만 외비 안정 성에 문제를 일으킬 수 있는 침습적인 코성형술 술기이다. 가

This is an Open Access article distributed under the terms of the Creative Commons Attribution Non-Commercial License (http://creativecommons.org/licenses/by-nc/4.0) which permits unrestricted non-commercial use, distribution, and reproduction in any medium, provided the original work is properly cited.
장 흔한 합병증은 출혈과 부종으로 절골술 시행 중 발생하는 연부조직 손상 또는 비배부 골막하 박리 중 발생하는 혈관 손 상이 주된 원인으로 생각된다.1) 최근에는 이러한 술 후 합병 증을 줄이고자 초음파를 이용한 절골도(osteotome)를 이용하 거나 비골 전체의 골막을 완전히 박리하여 절골술을 시행하 는 시도들도 이루어지고 있으나 ${ }^{2,3)}$ 합병증을 근본적으로 예방 하기는 어려우며 비골 골막을 완전히 박리하는 시술은 외비 안정성에 문제를 일으킬 수도 있다. 수술 후 발생하는 부종과 반상 출혈을 감소시키기 위해 술 중 스테로이드 사용과 저혈 
압 마취, 두부 거상 등 많은 방안들이 제시되고 실행되고 있 으나 근본적으로 합병증 발생을 막을 수 있는 방법은 없다. ${ }^{4}$

동양인의 비골은 비교적 작고 두꺼워서 크고 얇은 비골을 가진 서양인에 비해 정확한 절골술을 시행하기가 상대적으로 어려운 데다 내측, 외측 등 여러 절골술이 시행될수록 분쇄골 절(comminuted fracture)이 일어날 가능성이 높아지므로 주변 구조의 손상을 최소화하면서 정확히 시행하는 것이 매우 중 요하며5,6) 절골술의 빈도를 낮추어 사용할 수 있다면 술 후 여 러 합병증 발생을 감소시키는 데 도움이 되리라 생각된다. 저 자들은 휘어진 코 교정을 위한 코성형술을 시행하면서 만곡 의 볼록한(convex) 면에만 절골술을 시행하였음에도 만족스 런 교정을 얻은 증례들을 경험하였고 이를 분석하고자 한다.

\section{대상 및 방법}

\section{대상 및 설문조사}

2010년부터 2014년까지 병원에서 시행된 교정성 코성형술 (corrective rhinoplasty) 69예 중 골성 비배를 교정하는 데 편 측 절골술만을 사용한 9예를 대상으로 후향적으로 분석하 였다. 9 명의 환자 모두 비부비동 수술의 과거력이 없는 첫번 째 수술이었고 8명이 남자였으며 평균 연령은 36.7세(21 61 세)였다. 대상 환자는 모두 적극적인 수술적 치료에 동의할 정도의 코막힘을 호소하였고 병력 및 비강의 이학적 검사, 비 내시경 검사, 방사선학적 검사에서 비용종을 비롯한 비부비 동 질환이 관찰되지 않았다(Table 1). 본 연구는 인제대학교 상계백병원 임상시험심사위원회(Institutional Review Board) 의 승인 후 진행되었다(IRB 2016-10-003).

수술은 한 명의 전문의에 의해 시행되었고 한 명의 환자를 제외하고 수술 전과 수술 후 3 개월째 사진을 촬영하여 두 명 의 이비인후과 전문의가 수술 결과를 평가하였다. 술 후 만곡 의 교정된 결과는 우수(excellent), 양호(good), 변화 없음(no change), 악화(poor/worsening)으로 평가하였다(Table 1).
환자의 주관적 만족도를 조사하기 위한 설문조사는 수술 후 3개월째 시행하였으며 수술 전후의 코막힘 개선과 만곡의 정도에 대한 만족도, 수술 결과에 대한 미용적 관점에서의 만 족도를 시각화 연속형 척도 설문기법(visual analogue scale) 을 사용하여 비교하였다. 설문지에 $100 \mathrm{~mm}$ 도선을 표시하고 환자에게 주관적 만족도를 직접 표시하게 하였다. 변화가 없 거나 악화된 경우를 도선의 좌측 끝인 $0 \mathrm{~mm}$, 최고의 만족도 를 보이는 경우 우측 끝인 $100 \mathrm{~mm}$ 로 정하였다.

\section{수술 방법}

모든 환자는 전신마취하에 11번 칼로 경비주절개(transcolumella incision)를 이용한 비외접근법을 사용하였다. 경비주 절개 후 양측 외측으로 경계절개(marginal incision)와 연결하 여 비익연골과 비배부를 노출시켰고 비중격각(septal angle) 으로부터 양측 점막연골막과 점막골막 박리 후 상외측연골 과 비중격 연골을 분리하였다. 가능한 비전단부와 비배부 연 골을 $1 \mathrm{~cm}$ 이상 보존하며 비중격 연골을 채취하려 노력하였 고 절단된 비중격 연골을 디자인하여 편측 펼침 이식(unilateral spreader graft), 확장 비중격 이식(extended septal graft), 비 주지주(columella strut) 등의 방법을 사용하여 비중격 재건과 비첨 성형술식에 적절히 활용하였다. 모든 증례에서 펼침 이식 은 편측으로 시행되었는데 만곡된 비중격의 오목면(concave side)에 시행하였고 최소 4회의 매트리스 봉합으로 안정성을 확보하였다(Table 2). 펼침 이식을 시행한 것은 연골부 만곡을 교정하기 위함으로 C 또는 S자 만곡에서는 필수적으로 사용 되었고 straight type 만곡에서도 펼침 이식을 시행하였는데 외비가 직선으로 휘어진 경우도 비강 내부에서는 비중격 연 골부의 만곡이 관찰되는 경우가 많았고 현저한 만곡이 확인 되지 않는 경우에도 비첨 성형 등을 위하여 비중격 연골을 채취하므로 연골부 지지구조가 약해져 이를 보강하기 위해 서였다.

연골부 만곡과 비첨에 대한 교정 술식이 종료된 후 수술의

Table 1. Details of patients who had corrective rhinoplasty with unilateral osteotomy

\begin{tabular}{|c|c|c|c|c|c|}
\hline Case & Sex/age & Types of deviation & Other esthetic problem & Surgical outcome & $\mathrm{F} / \mathrm{U}(\mathrm{m})$ \\
\hline 1 & $M / 26$ & S shape & Pseudo hump & Good & 3 \\
\hline 2 & $M / 42$ & Straight & & Excellent & 12 \\
\hline 3 & $M / 61$ & Reverse C shape & & Excellent & 3 \\
\hline 4 & $\mathrm{~F} / 42$ & Straight & & Good & 3 \\
\hline 5 & $M / 58$ & Reverse C shape & Saddle nose & Good & 3 \\
\hline 6 & $M / 39$ & C shape & & Excellent & 12 \\
\hline 7 & $M / 21$ & Straight & & Good & 3 \\
\hline 8 & $M / 26$ & Reverse C shape & & Excellent & 2 \\
\hline 9 & $M / 33$ & C shape & & Excellent & 12 \\
\hline
\end{tabular}

F/U: follow up period 
최종 단계에서 골성 비배 만곡 교정을 위해 절골술을 시행하 였다. 대부분의 증례에서 절골술을 행하기 전 골성 비배의 불 규칙한 표면을 줄(rasp)을 사용하여 매끄럽게 만들었다. 모든 증례에서 만곡된 골성 비배의 볼록(convex)면에 먼저 절골술 을 시행하고 내향골절 시킨 후 교정이 충분하다고 판단되면 반대측 절골술은 시행하지 않았다. 만족할 만한 교정이 이루 어지지 않으면 반대측 오목(concave)면에 절골술을 추가 시행 하였다. 편측 절골술을 시행한 모든 증례에서 볼록면에는 내 측(medial), 외측(lateral) 절골술이 동시에 시행되었고 오목면 에는 절골술이 시행되지 않았다. 필요에 따라 대퇴근막(fascia lata)과 채취한 비중격 연골을 이용하여 적절한 위장이식(camouflage graft)을 만들어 오목면을 보충하였고 모든 환자에서 두께를 다르게 하여 비배부 코높임술을 시행하였으며 사용한 재료는 대퇴근막, gore tex, silicone이었다(Table 2).

\section{결 과}

편측 절골술만을 사용한 9 예의 환자군에서 동반된 외비

Table 2. Summary of corrective rhinoplasty procedures

\begin{tabular}{ccll}
\hline Case & Approach & \multicolumn{1}{c}{ Procedure } & Graft materials \\
\hline 1 & External & ST, ESG, USpG & Gore tex \\
2 & External & ST, CS, USpG & Fascia lata \\
3 & External & ST, ESG, USpG & Gore tex \\
4 & External & ST, CS, USpG & Gore tex \\
5 & External & ST, ESG, USpG & Fascia lata \\
6 & External & ST, ESG, USpG & Fascia lata \\
7 & External & ST, CS, USpG & Silicone \\
8 & External & ST, ESG, USpG & Fascia lata \\
9 & External & ST, ESG, USpG & Fascia lata \\
\hline
\end{tabular}

ST: septoturbinoplasty, ESG: extended septal graft, USpG: unilateral spreader graft, CS: columella strut
만곡의 분류는 C 또는 reverse C type이 5명, S type이 1명, straight type이 3명이었다. 휘어진 코 외 미용적 문제는 측면 에서 심하게 주저앉은 안장코가 1 명, 외상으로 인한 가성비혹 (pseudohump)이 1명이었다(Table 1). 안장코는 술전 측면부 사진에서 비근점에서 비첨까지 일직선을 그어 하방으로 저명 한 함몰이 있는 경우로 가성비혹은 비배가 높지 않음에도 상 대적으로 낮은 비근부와 비첨 때문에 비혹처럼 보이는 경우 로 판단하였다. 모든 환자에게서 만족스러운 교정이 이루어 졌으며 심한 부종과 반상 출혈, 감염, 이식물 이탈, 현저한 지 주 반흔 등의 부작용도 나타나지 않았다. 양측 절골술과 편 측 절골술 두 군의 환자 간에 출혈과 부종의 정도를 정량화 하여 비교하지는 않았으나 수술 후 1 일째 경과기록상 양측 절골술 환자 52 명 중 11 명에서 현저한 부종 소견이 있다고 기록되었으나 편측 절골술 환자 9명에서는 특별히 부종에 대 한 소견이 기록되어 있지 않았다. 수술 후의 주관적 만족도 측 정을 위해 시행한 설문조사에서 $100 \mathrm{~mm}$ 만점을 기준으로 코막힘 개선 만족도 $82 \mathrm{~mm}$, 휘어진 코 교정 만족도 $85 \mathrm{~mm}$, 전체적인 수술 결과에 대한 만족도 $79 \mathrm{~mm}$ 였다(Fig. 1). 절골 술을 시행하지 않은 환자 6예와 설문 기록을 찾지 못한 2명 을 제외하고 양측 절골술을 모두 사용하여 교정한 52예 환 자들의 만족도는 각각 $80,83,76 \mathrm{~mm}$ 였고 편측 절골술만을 시행한 환자들과 차이를 보이지 않았다(Fig. 1). 현저한 불만 족을 표시한 환자는 없었으며 외비 교정 만족도보다 전체적 인 수술 결과 만족도가 다소 낮은 원인을 분석한 결과 2 명의 환자가 미간부 높이가 불충분하다고 호소하였으며, 1 명의 환 자에서 코끝이 다소 뭉툭하다고 생각하기 때문이었고 이러 한 이유로 재수술을 시행한 환자는 없었다.
Fig. 1. Patient's subjective evaluation on postoperative improvement of functional and aesthetic results between patients with unilateral osteotomy $(n=9)$ and patients with bilateral osteotomy $(n=52)$.

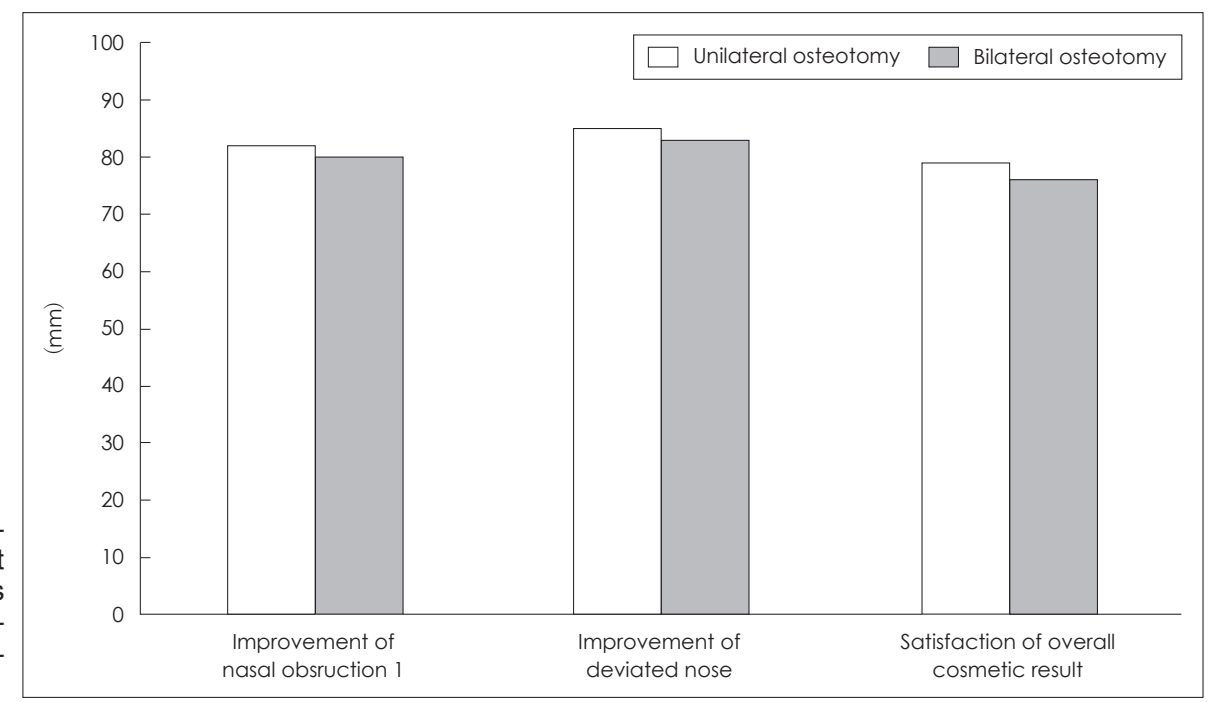



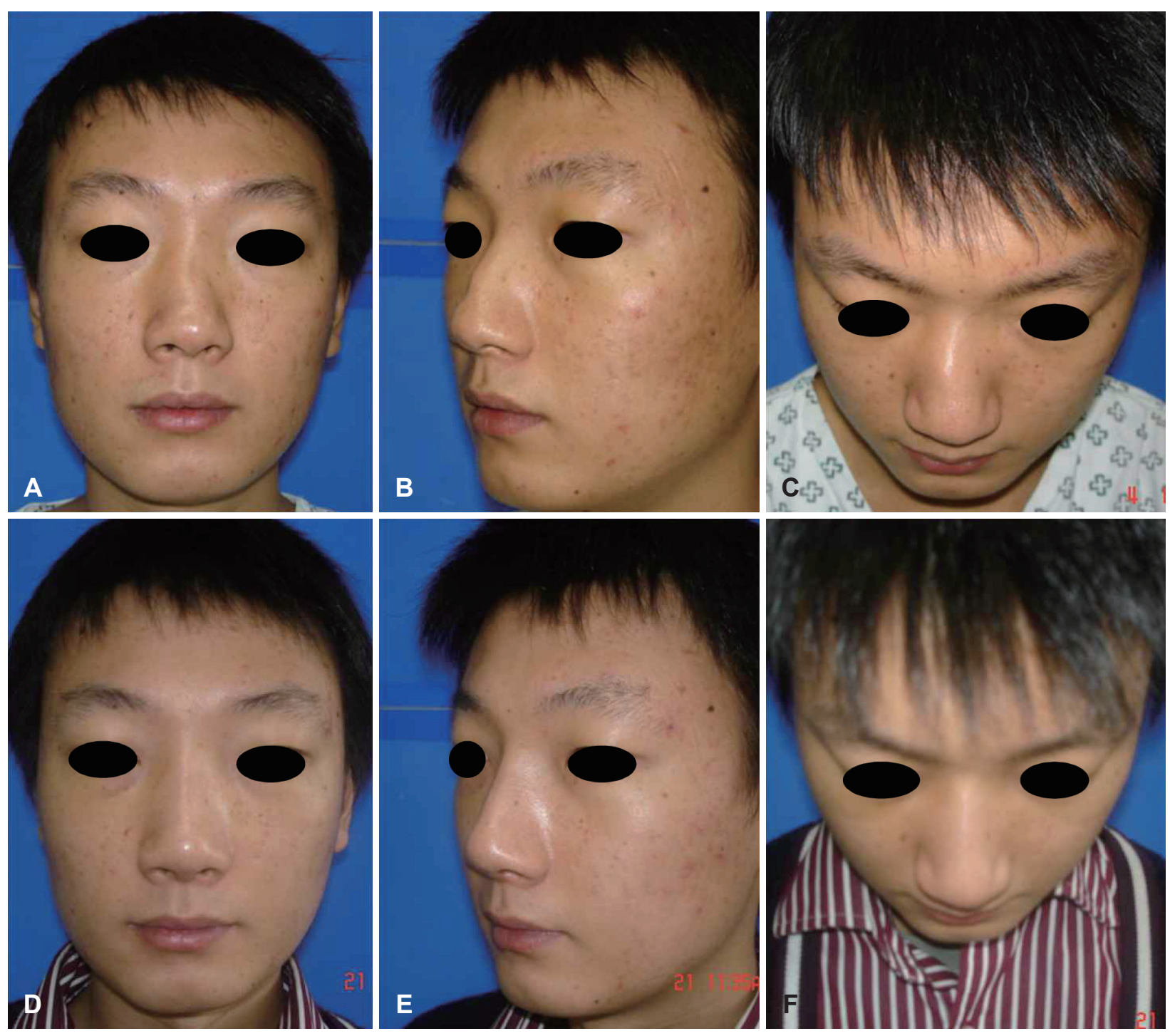

Fig. 2. Facial profiles of case 1, S-shaped deviated nasal deformity is shown on the preoperative images, deviated nose was corrected after corrective rhinoplasty with right unilateral osteotomy. Before the surgery (A, B, and C). 3 months after the surgery (C, D, and F).

\section{고 찰}

코성형술에서 사용되는 절골술은 골성 외비의 만곡을 교정 하거나 비폭을 줄이고 비혹 제거 후 발생하는 골성 비배 결손 부를 줄여주는 핵심적인 시술이지만 비밸브 허탈(nasal valve collapse)을 일으키거나 골성 비배 안정성을 악화시키고 미용 적 비대칭을 유발할 수도 있는 침습적인 술기이다. 임상에서 의 사용빈도는 매우 높은 편으로 동양인의 휘어진 코를 교정 하는 데 쓰이는 5 가지 핵심적인 술식 중에서 $82.8 \%$ 의 빈도로 비중격 성형술에 이어 두 번째로 흔하게 사용되고 있다. ${ }^{7}$

그 종류도 Deneeke 등 $^{8}$ 이 비혹 제거 후 비배를 좁히는 절 골술에 대해 처음으로 보고한 뒤로 내측 절골술, 외측 절골 술, 중간 절골술, 경피적 절골술 등 다양하게 추가되어 왔는데
모두가 효과적이고 성공적인 골성 비배의 교정을 위한 시도 라 할 수 있지만 여러 절골술이 적극적으로 사용될수록 합병 증 발생 가능성 또한 높아질 수밖에 없다. 절골술의 접근방법 도 다양하여 비내접근법, 구강접근법, 경피접근법 등 ${ }^{9-12)}$ 이 사 용되는데 이러한 형태의 절골술들은 골성 비배의 만곡을 효 과적으로 교정하고 연부조직 손상과 비골 안정성을 유지하 기 위함이지만 효과를 최대화하고 부작용을 최소화시키는 방법은 정해진 바 없는 데다 동양인의 비골은 서양인에 비해 상대적으로 작고 두꺼워서 절골술이 반복되어 시행될수록 골 성 비배 안정성에 문제가 생길 가능성이 높기 ${ }^{13}$ 에 주위 연부조 직 손상을 줄이면서 정확히 시행하도록 하는 원칙이 더욱 중 요하다 하겠다.

반면 이러한 침습적인 시술인 절골술의 빈도를 낮추어 사용 

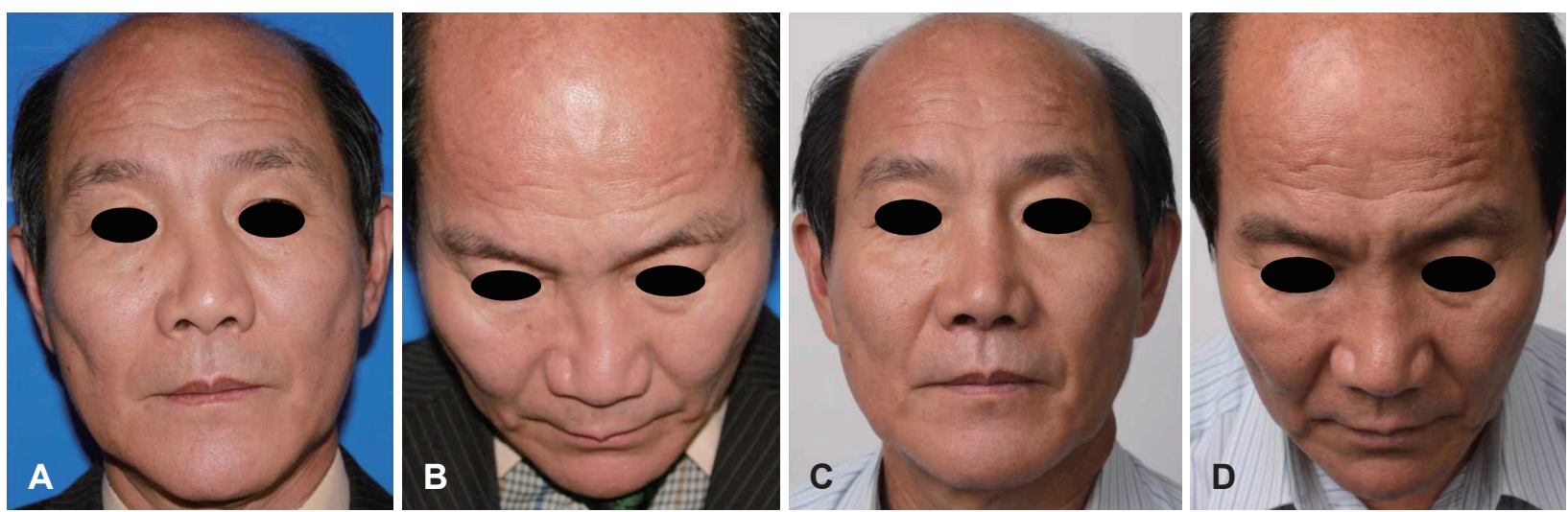

Fig. 3. Facial profiles of case 2, straight type deviated nasal deformity is shown on the preoperative images, deviated nose was corrected after corrective rhinoplasty with left unilateral osteotomy. Before the surgery (A and B). 3 months after the surgery (C and D).
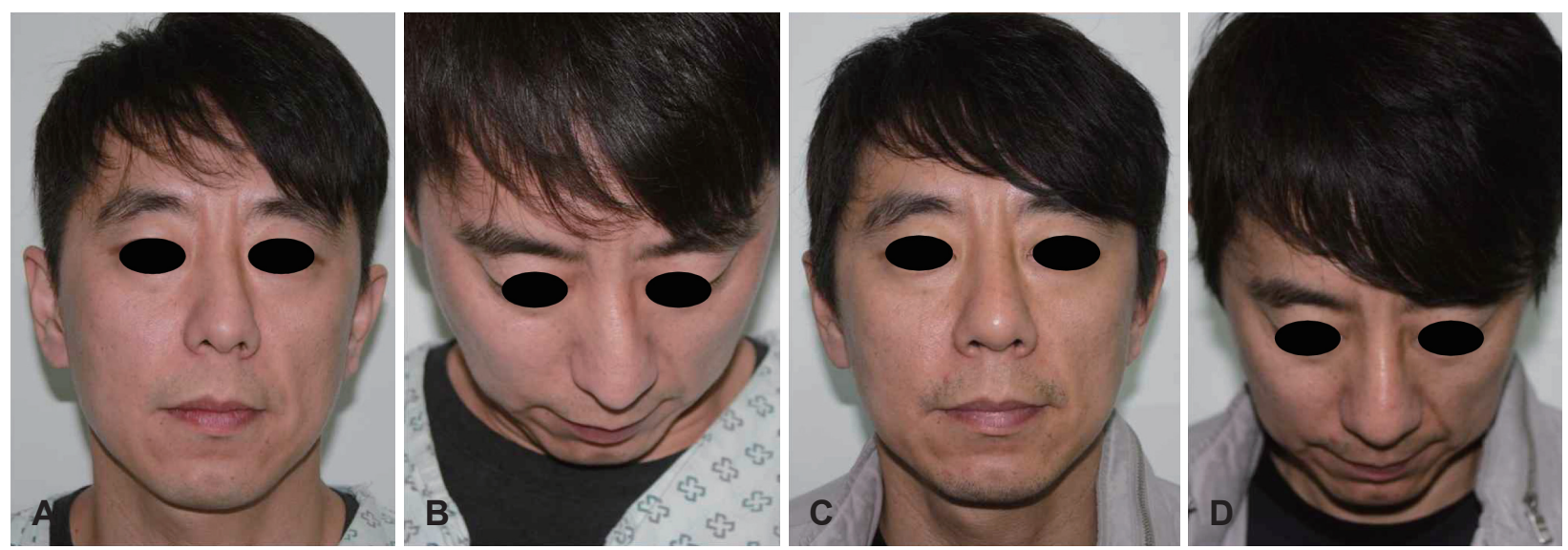

Fig. 4. Facial profiles of case 3 , reverse C-shaped deviated nasal deformity is shown on the preoperative images, however, deviated nose was corrected after corrective rhinoplasty with left unilateral osteotomy. Before the surgery (A and B). 3 months after the surgery $(\mathrm{C}$ and $\mathrm{D})$.

할 수 있다면 술 후 합병증 발생을 감소시키고 환자의 회복 기간도 앞당길 수 있으므로 술자들은 적극적인 연골부 교정과 골부 rasping, 위장이식(camouflage graft) 등을 이용하여 절 골술 빈도를 줄여나가고 있다. 동양인의 절골술 사용빈도나 시행 순서에 관한 연구는 많지 않으나 편측 절골술만을 사용 하여 40예의 휘어진 코를 교정한 연구가 있는데, ${ }^{21}$ 모든 증례 에서 휘어진 코의 오목면에 외측 절골술만을 사용하고 반대측 볼록면에는 전방 쐐기 절제(anterior wedge resection)를 한 뒤 green stick fracture 시키고 2-0 철사를 사용하여 골절부 의 내측 함입을 막는 봉합을 하는 방법을 사용하였다. 저자 들의 연구와는 반대로 오목면에만 편측 절골술을 시행한 경 우로 본 연구에서는 볼록면에 내측, 외측 절골술을 모두 시 행하고 내향 골절시킨 뒤 오목면에 위장이식을 시행하여 교 정하였으므로 차이가 있으며, 보다 침습적이며 wire 사용과 관련해 수술 시간이 더 소요되고 외부에서 철사가 만져지는 문제가 발생할 수도 있을 것으로 판단된다. 또 다른 연구에 서는 절골술 후 비배 폭 변화를 정량적으로 분석하고자 내
측 절골술 시행 없이 외측 절골술만을 시행 후 비골을 내향 골절 시켜 비배폭을 줄이는 시도가 있었다. ${ }^{14}$ 하지만 서양인을 대상으로 코축소술(reduction rhinoplasty) 환자만을 대상으 로 시행한 연구였으므로 휘어진 코를 교정하는 연구와는 차 이가 있다.

일반적으로 만곡의 분류에 따라 수술 결과의 차이를 보이 는 것으로 되어 있고 골부와 연골부가 같은 방향으로 휜 직선 (straight) 타입 만곡이 교정하기 가장 어려운 것으로 알려져 있는데 이러한 경우에도 편측 절골술만을 이용하여 교정이 가능한 증례가 있었다(Figs. 2, 3, and 4).

대상의 수가 많지 않은 단점이 있으나 본 연구에서 총 69예 중 9예인 $13 \%$ 의 휘어진 코 환자들에게서 편측 절골술만으 로 성공적인 교정이 이루어졌으므로 적은 확률은 아니라고 생각된다. 또한 모든 경우에서 비배부 삽입물을 사용하였는 데 비배를 높이는 것뿐만 아니라 휘어진 코 교정 후 코를 곧 아 보이게 하고 촉진 시 불규칙한 표면을 부드럽게 만져지게 하는 효과가 있었다. 삽입물로는 대퇴근막을 가장 많이 사용 
하였는데 비근부와 비배의 두께를 달리하여 사용할 수 있어 환자 만족도가 높았다. 일반적으로 동양인이 서양인에 비해 피부와 연부조직이 두꺼워 코 하부구조 경도의 비대칭이 덜 도드라지는 경향이 있는 데다 비배 높임술을 함께 원하는 경 우가 많으므로 위장이식과 더불어 비배 삽입물을 적극적으 로 사용하는 것이 바람직하다고 생각된다.

수술 결과 전반에 대한 환자들의 주관적인 만족도가 휘어 진 코 교정에 국한된 만족도보다 다소 떨어지는 경향이 있었 는데 휘어진 코의 불충분한 교정보다는 미간부 높이가 불충 분하다고 생각하거나 코끝의 모양과 높이에 대한 불만이었 다(Fig. 1). 이들은 이비인후과 전문의가 평가한 수술 결과에서 도 양호(good)로 평가되었으나 휘어진 코 교정 정도만 따로 판단할 때는 우수한 결과를 보였다.

1977년에 Webster 등다)이 굴곡형 외측 절골도를 이용하여 high-low-high 절골술을 계획하고 시행하여 기도의 안정성을 확보하고자 노력한 이후로 많은 방법들이 소개되고 있으며 최근에는 초음파를 이용한 절골도를 이용하거나 비골 전체 의 골막을 완전히 박리하여 절골술을 시행하는 시도들도 이루 어지고 있으나 ${ }^{3)}$ 완전히 안전한 절골술은 정립되어 있지 않으 며 주변 연부조직의 손상을 최소화하고 두께가 얇은 절골도 로 세심하게 시행하는 원칙을 지키는 것이 중요하다. 실제로 임상에서는 휘어진 코의 골부를 교정할 때 대부분의 술자들 이 증례의 개별적 특성에 맞추어 양측 절골술이나 편측 절골 술 또는 절골술을 시행하지 않고 골부를 적절히 줄질(rasping) 한 뒤 적절한 위장이식을 사용하여 만족스런 결과를 얻고 있 어 본 연구가 새로운 술기를 소개하는 것은 아니지만 교과서 에서 편측 절골술이나 양측 절골술의 적응증을 기술하고 있 지는 않다. 증례 수가 많지 않고 그 결과를 정량화하여 평가 하기 힘들다는 제한점이 있으나 만곡의 여러 타입과 무관하 게 절골술을 시행할 때 항상 휘어진 코의 볼록면에 먼저 절
골술을 시행하고 위장술을 적절히 활용하여 휘어진 코를 성 공적으로 교정한 증례들이 있으므로 하나의 참고자료로 사 용할 만하다고 생각된다.

\section{REFERENCES}

1) Thomas JR, Griner NR, Remmler DJ. Steps for a safer method of osteotomies in rhinoplasty. Laryngoscope 1987;97(6):746-7.

2) Gerbault O, Daniel RK, Kosins AM. The role of piezoelectric instrumentation in rhinoplasty surgery. Aesthet Surg J 2016;36(1): 21-34.

3) Taşkın Ü, Batmaz T, Erdil M, Aydın S, Yücebaş K. The comparison of edema and ecchymosis after piezoelectric and conventional osteotomy in rhinoplasty. Eur Arch Otorhinolaryngol 2017;274(2):861-5.

4) Ong AA, Farhood Z, Kyle AR, Patel KG. Interventions to decrease postoperative edema and ecchymosis after rhinoplasty: a systematic review of the literature. Plast Reconstr Surg 2016;137(5):1448-62.

5) Jung YK. Tailored correction of deviated nose. Korean J Otorhinolaryngol-Head Neck Surg 2013;56:684-91.

6) Jang YJ, Wang JH, Sinha V, Lee BJ. Percutaneous root osteotomy for correction of the deviated nose. Am J Rhinol 2007;21(4):515-9.

7) Jin HR, Lee JY, Shin SO, Choi YS, Lee DW. Key maneuvers for successful correction of a deviated nose in Asians. Am J Rhinol 2006; 20(6):609-14.

8) Deneeke HJ, Meyer R. Plastic surgery of head and neck: corrective and reconstructive rhinoplasty. 1st ed. New York: Springler-Verlag New York Inc.;1967. p.48-67.

9) Hilger JA. The internal lateral osteotomy in rhinoplasty. Arch Otolaryngol 1968;88(2):211-2.

10) Parsa FD. Intraoral versus intranasal approach to lateral osteotomy. Plast Reconstr Surg 1992;90(2):341.

11) Goldfarb M, Gallups JM, Gerwin JM. Perforating osteotomies in rhinoplasty. Arch Otolaryngol Head Neck Surg 1993;119(6):624-7.

12) Jang YJ, Oh JK. Rhinoplasty using percutaneous osteotomy. Korean J Otolaryngol-Head Neck Surg 2000;43(9):952-5.

13) Kim YH, Jung CY, Chung KJ, Lee JH, Kim TG. A systematized strategy in corrective rhinoplasty for the Asian deviated nose. Ann Plast Surg 2017;79(1):7-12.

14) Kortbus MJ, Ham J, Fechner F, Constantinides M. Quantitative analysis of lateral osteotomies in rhinoplasty. Arch Facial Plast Surg 2006;8 (6):369-73.

15) Webster RC, Davidson TM, Smith RC. Curved lateral osteotomy for airway protection in rhinoplasty. Arch Otolaryngol 1977;103(8):454-8. 